\title{
Non-Fullerene Small Molecule Electron-Transporting Materials for Efficient p-i-n Perovskite Solar Cells
}

\author{
Da-Seul Choi, Sung-Nam Kwon * and Seok-In Na * \\ Graduate School of Flexible and Printable Electronics, LANL-JBNU Engineering Institute-Korea, \\ Jeonbuk National University, 567 Baekje-daero, Deokjin-gu, Jeonju-si 54896, Korea; ektmf6175@jbnu.ac.kr \\ * Correspondence: dasom2u@jbnu.ac.kr (S.-N.K.); nsi@jbnu.ac.kr (S.-I.N.)
}

Received: 3 April 2020; Accepted: 12 May 2020; Published: 31 May 2020

\begin{abstract}
PC}_{61} \mathrm{BM}$ is commonly used in perovskite solar cells (PSC) as the electron transport material (ETM). However, $\mathrm{PC}_{61} \mathrm{BM}$ film has various disadvantages, such as its low coverage or the many pinholes that appear due to its aggregation behavior. These faults may lead to undesirable direct contact between the metal cathode and perovskite film, which could result in charge recombination at the perovskite/metal interface. In order to overcome this problem, three alternative non-fullerene electron materials were applied to inverted PSCs; they were evaluated on suitability as electron transport layers. The roles and effects of these non-fullerene ETMs on device performance were studied using photoluminescence (PL) measurements, field emission scanning electron microscopy (FE-SEM), atomic force microscopy (AFM), internal resistance in PSC measurements, and conductive atomic force microscopy (C-AFM). It was found that one of the tested materials, IT-4f, showed excellent electron extraction ability and was associated with reduced recombination. The PSC with IT-4f as the ETM produced better cell-performance; it had an average PCE of $11.21 \%$, which makes it better than the ITIC and COi8DFIC-based devices. Finally, IT- $4 \mathrm{f}$ was compared with $\mathrm{PC}_{61} \mathrm{BM}$; it was found that the two materials have quite comparable efficiency and stability levels.
\end{abstract}

Keywords: perovskite solar cells; non-fullerene small molecules; electron transporting layer; lowest unoccupied molecular orbital energy level; charge extraction and recombination

\section{Introduction}

Perovskite solar cells (PSCs) based on organo-metal halides have received a lot of attention recently due to their high efficiencies, facile solution processes, and low manufacturing costs [1-3]. The power conversion efficiency (PCE) of PSCs has increased rapidly and continuously since it was first reported in 2009; a PCE recently achieved 25.2\% efficiency, which is comparable to silicon solar cells [4]. Hence, PSC is a highly promising candidate as an alternative energy source that can not only be commercialized through roll-to-roll processing, but can also prevent energy exhaustion and environmental pollution [2,5].

Currently, various PSC architectures are being actively studied; these include mesoporous structured, n-i-p structured, and p-i-n structured PCEs; over 20\% efficiency has been gained using each architecture $[4,6,7]$. Although mesoporous-structure-based PSCs have shown quite high performances, the formation of mesoporous or compact $\mathrm{TiO}_{2}$ layers generally requires high thermal energy $\left(>450{ }^{\circ} \mathrm{C}\right.$ treatment), which limits continuous processes and scaled-up manufacturing for tandem and flexible PSC applications [8,9]. Regarding one of the other architectures, it has been reported that n-i-p structured PSCs, which use metal oxide as their electron transport layer (ETL), have hysteresis behavior [10-12]. Meanwhile, p-i-n structured PSCs, which are generally composed of a transparent conductive electrode/hole transport layer (HTL)/perovskite/ETL/metal electrode structure, are known to produce hysteresis-free PSCs through low-temperature and continuous processes [11-14]. 
In the $p-i-n$ structured PSC, fullerene and its derivatives are widely used. In particular phenyl- $\mathrm{C}_{61}$-butyl ester $\left(\mathrm{PC}_{61} \mathrm{BM}\right)$ is commonly used as the ETL due to its high electron mobility and dissolution in non-polar solvents [13-15]. In addition, it has been demonstrated that $\mathrm{PC}_{61} \mathrm{BM}_{\mathrm{can}}$ provide a trap passivation function in the perovskite layer by interacting with negatively charged under-coordinated halide ions or $\mathrm{Pb}-\mathrm{I}$ anti-site defects; this results in improved performance of the PSCs [16-18]. Despite these advantages, PC 61 BM ETL has some drawbacks to address; due to the low solubility and viscosity of the solution, and the cohesive behavior of $\mathrm{PC}_{61} \mathrm{BM}$, it is difficult to form a uniform and defect-free $\mathrm{PC}_{61} \mathrm{BM}$ film on the perovskite layer $[10,19]$. Uneven and defective $\mathrm{PC}_{61} \mathrm{BM}$ films could cause unexpected direct contact between the metals and perovskite, resulting in recombination of photogenerated charges and degradation of device performance [8]. Moreover, mechanical analysis of the p-i-n PSC structure reveals that the $\mathrm{PC}_{61} \mathrm{BM}$ layer is the most fragile and susceptible to rupture. All the mentioned problems suggest that replacing $\mathrm{PC}_{61} \mathrm{BM}$ would lead to much enhanced device stability [14,20,21].

Fundamentally, to solve these problems completely, it is best to replace fullerene. Various studies have recently been conducted on the ETL in PSCs being composed of non-fullerene-based, small-molecule acceptor materials [14,22]. The motivation for these experiments could be because the fact non-fullerene small molecules (NFSMs) are easier and cheaper to synthesize than $\mathrm{PC}_{61} \mathrm{BM}$, and the various properties of NFSMs can be also easily controlled by modification to the side chains [22]. For example, the small molecule 3,9-bis(2-methylene-(3-(1,1-dicyanomethylene)-indanone)-5,5,11,11tetrakis(4-hexylphenyl)-dithieno[2,3-d:2', 3'- $\left.\mathrm{d}^{\prime}\right]$-s-indaceno[1,2-b:5,6-b']-dithiophene (ITIC), which is based on an indacenodithiophene (IDT) chemical backbone, has been used as an electron acceptor in organic solar cells, and these cells achieved comparable efficiencies with $\mathrm{PC}_{61} \mathrm{BM}[14,22,23]$. ITIC has also been used to optimize the ETL of n-i-p structured PSCs; an ultra-thin ITIC layer was inserted between the $\mathrm{TiO}_{2}$ ETL and perovskite active layers to improve photovoltaic performance [24]. In our previous research, we also confirmed the ITIC's feasibility as the ETL of PSCs based on using $\mathrm{MAPbI}_{3}$ as the photovoltaic active layer [22]. Meanwhile, Angmo et al. demonstrated that when industry-relevant slot-die coating methods are used, ITIC is a good candidate to replace PC $_{61}$ BM in ambient-processed PSCs. In fact, ITIC in nanofiber form improves device mechanical integrity when compared with the aggregated form of $\mathrm{PC}_{61} \mathrm{BM}$ film [14]. In this regard, various NFSMs based on IDT chemical backbone have been reported with a view of using them as $\mathrm{PC}_{61} \mathrm{BM}$ alternatives [25-27]. However, there have been few trials of these NFSMs being used in actual perovskite solar cells [14,16,22]. Thus, it is important that a practical comparison to confirm whether they are better ETL candidates be carried out.

In this respect, this work began as a study to solve the problems of PCBM and eventually find an electron transport material that can replace it. We first selected IDT-backbone-based materials as an alternative electron transport materials (ETMs); it was reported IDT-backbone-based materials have relatively good electron mobility and energy levels compared to other ETMs [25-27]. Three types of NFSMs with the same IDT backbone structure but different electronic mobility and energy levels were selected, and device performance changes were compared accordingly: ITIC, IT-4f (3,9-bis(2-methylene-((3-(1,1-dicyanomethylene)-6,7-difluoro)-indanone))-5,5,11,11-tetrakis(4hexylphenyl)-dithieno[2,3-d:2' ,3' - $\left.\mathrm{d}^{\prime}\right]$-s-indaceno[1,2-b:5,6-b']dithiophene), and COi8DFIC (2,2' -[[4,4,

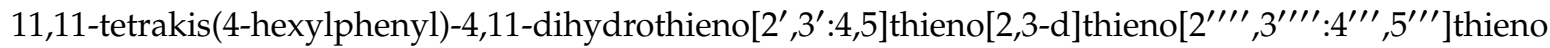
$\left[2^{\prime \prime \prime}, 3^{\prime \prime \prime}: 4^{\prime \prime}, 5^{\prime \prime}\right]$ pyrano[2" $\left., 3^{\prime \prime}: 4^{\prime}, 5^{\prime}\right]$ thieno[2', $\left.3^{\prime}: 4,5\right]$ thieno[3,2-b]pyran-2,9-diyl]bis[methylidyne(5,6difluoro)]]). These NFSMs were systematically compared for better performance using $\mathrm{Cs}_{0.17}$ $\left(\mathrm{FA}_{0.9} \mathrm{MA}_{0.1}\right)_{0.83} \mathrm{~Pb}\left(\mathrm{I}_{0.87} \mathrm{Br}_{0.13}\right)_{3}$ (CsMAFA)-based perovskite solar cells. Considering the energy level and electronic mobility, IT-4F, which has a lower LUMO and better electronic mobility than ITIC and COi8DFIC, was expected to show the best device performance. Consequently, it was found that IT-4f showed excellent electron extraction ability and associated reduced recombination. PSCs with IT-4f as the ETM had a relatively high average PCE of 11.21\% compared to ITIC and COi8DFIC-based devices, and showed comparable cell-performance with $\mathrm{PC}_{61} \mathrm{BM}$-bsed devices. 


\section{Materials and Methods}

For the fabrication of p-i-n structured PSCs with ETMs based on various NFSMs, firstly, pre-patterned indium tin oxide (ITO) glass-substrate (AMG-Tech) was treated with $\mathrm{UV} / \mathrm{O}_{3}$ for $30 \mathrm{~min}$. Next, for the HTL layer, NiO nanoparticle solution (NiO NPs, 2.5 wt \% NiO ethanol, 1-material Inc., Dorval, QC, Canada) was spin-coated onto UV-treated ITO at $4000 \mathrm{rpm}$ for $40 \mathrm{~s}$ and annealed at

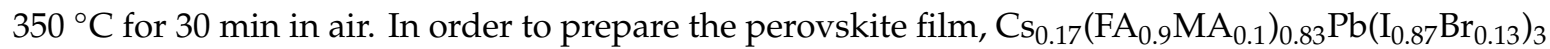
(CsMAFA) perovskite precursor solution was prepared by dissolving $568 \mathrm{mg}$ lead (II) iodide ( $\mathrm{PbI}_{2}$, 99\%, TCI, Tokyo, Japan), $80 \mathrm{mg}$ lead(II) bromide $\left(\mathrm{PbBr}_{2}, 99 \%\right.$, TCI), $187 \mathrm{mg}$ formamidinium iodide (FAI, 98\%, Great Cell Solar, QLD, Australia), $66 \mathrm{mg}$ cesium iodide (CsI, 99.99\%, Sigma-Aldrich, St. Louis, MO, USA), and $12 \mathrm{mg}$ methylammonium bromide (MABr, $\geq 99 \%$, Sigma-Aldrich) in $0.8 \mathrm{~mL}$ of N,N-dimethylformamide (DMF, 99.8\%, Sigma-Aldrich) and $0.2 \mathrm{~mL}$ of dimethyl sulfoxide (DMSO, 99.7\%, Sigma-Aldrich) in an $\mathrm{N}_{2}$-filled glove box ( $<1 \mathrm{ppm} \mathrm{O}_{2}$ and $\left.\mathrm{H}_{2} \mathrm{O}\right)$. The perovskite solution was spin-coated at $500 \mathrm{rpm}$ for $5 \mathrm{~s}$ and $5000 \mathrm{rpm}$ for $45 \mathrm{~s}$ in a two-step process. During the second coating step, $0.4 \mathrm{~mL}$ of chlorobenzene (CB, 99.8\%, Sigma-Aldrich) was dropped on the spinning substrate $30 \mathrm{~s}$ before the end of the spin-coating; the film was then dried at $100{ }^{\circ} \mathrm{C}$ for $10 \mathrm{~min}$. ITIC (1-material Inc.), IT-4f (1-material Inc.), and COi8DFIC (1-material Inc.) dispersed in 1,2-dichlorobenzene (DCB, 99\%, Sigma-Aldrich) were spin-coated on the perovskite layer at $5000 \mathrm{rpm}$ for $50 \mathrm{~s}$, in which the thicknesses of NFSMs were optimized approximately $11.18 \mathrm{~nm}(5 \mathrm{mg} / \mathrm{mL}$ of ITIC), $10.10 \mathrm{~nm}$ (8 mg/mL of IT-4f), and $0.84 \mathrm{~nm}\left(8 \mathrm{mg} / \mathrm{mL}\right.$ of COi8DFIC), respectively. PC ${ }_{61} \mathrm{BM}$ (Nano-C, Westwood, MA, USA) dispersed in DCB $(20 \mathrm{mg} / \mathrm{mL})$ was spin-coated on the perovskite layer at $5000 \mathrm{rpm}$ for $50 \mathrm{~s}$. A finger-shaped mask was accurately machined so that the vertically projected electrode and ITO overlap areas (active areas) were $0.0464 \mathrm{~cm}^{2}$. Then, using the corresponding mask, bathocuproine (BCP, 98\%, Alfa Aesar, Ward Hill, MA, USA) (3 nm) and Ag electrodes (100 nm) were independently deposited to be separated from each other by a thermal evaporator under a pressure of $10^{-6}$ torr. Thus, as shown in Figure 1 , the electrodes were configured independently to form one device, and statistical photovoltaic cell parameters were analyzed for each independent electrode.

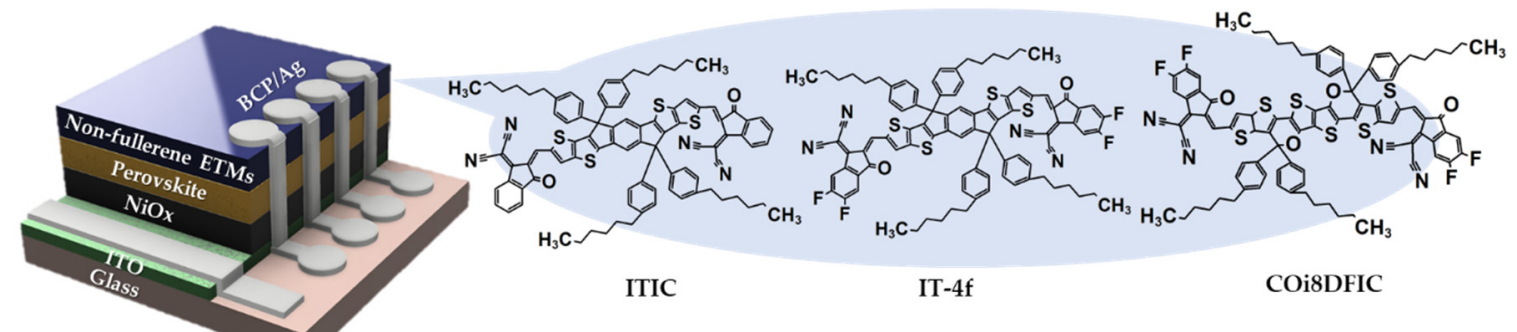

Figure 1. Schematic illustration of the molecular structure of the selected electron transport materials (ETMs) and the device architecture of the inverted, planar, non-fullerene perovskite solar cells (PSC).

The photocurrent density-voltage $(\mathrm{J}-\mathrm{V})$ characteristics of the PSCs were evaluated using a Keithley 2400 (Keithley Instruments Inc., Cleveland, OH, USA) and Oriel solar simulator (Sol3A, Class AAA, Newport, Irvine, CA, USA) under the AM $1.5 \mathrm{G}\left(100 \mathrm{~mW} / \mathrm{cm}^{2}\right)$ with a standard Si-reference solar cell certified by the International System of Units (SI) (SRC 1000 TC KG5 N, VLSI Standards, Inc., Milpitas, CA, USA). Steady-state photoluminescence (PL), transient photovoltage (TPV), and transient photocurrent (TPC) measurements were performed using a spectrophotometer (SHIMADZU, Kyoto, Japan, RF-6000) and an organic semiconductor parameter test system (T4000, McScience, Suwon, Korea) with oscilloscope (DPO-2014B, Tektronix, Beaverton, OR, USA). The properties of film were examined by looking at surface images while checking its properties and work function using atomic force microscopy (AFM, XE7, Park System, Suwon, Korea), field emission scanning electron microscopy (FE-SEM, JSM-7100F, JEOL Ltd., Tokyo, Japan), ultraviolet photoelectron spectroscopy 
(UPS, Nexsa-XPS system, Thermo Scientific Ltd., Waltham MA, USA) with He I (21.2 eV) as the photon source, and conductive atomic force microscopy (C-AFM, Bruker, Billerica, MA, USA, MultiMode 8).

\section{Results and Discussion}

To investigate the impacts of the selected non-fullerene ETMs (ITIC, IT- $4 \mathrm{f}$, and COi8DFIC) on the performance of the perovskite solar cells (PSCs) and determine the optimum concentration of non-fullerene ETMs, we fabricated inverted planar PSCs with various concentrations of non-fullerene ETMs. Figure 1 illustrates the molecular structure of the selected non-fullerene ETMs and the device architecture of the inverted planar PSC: glass/ITO/HTL/perovskite/ETL/metal electrode. The non-fullerene ETM layers with various concentrations were spin-coated on the pre-prepared perovskite substrate, and the J-V curves of the PSC based on this are shown in Figure S1. The average device efficiency of the PSC with ITIC increased from $4.99 \%$ to $8.22 \%$ as the concentration of ITIC increased from 2 to $5 \mathrm{mg} / \mathrm{mL}$, and decreased $5.16 \%$ as the concentration of ITIC further increased to $12 \mathrm{mg} / \mathrm{mL}$. As shown in Figure S1, similar trends were observed for the $\mathrm{J}_{\mathrm{SC}}, \mathrm{V}_{\mathrm{OC}}$, and FF, for IT-4F and COi8DFIC. Moreover, similar trends were shown at slightly higher concentrations. Consequently, optimal device performance was obtained at ITIC of $5 \mathrm{mg} / \mathrm{mL}$, IT-4f of $8 \mathrm{mg} / \mathrm{mL}$, and COi8DFIC of 8 $\mathrm{mg} / \mathrm{mL}$, respectively.

To better study the impact of the selected non-fullerene ETMs on the performance of the PSC, we performed additional statistical analysis on more than 15 devices under optimal concentration conditions. Figure 2 shows the typical J-V curves and the statistical photovoltaic cell parameters of the PSCs with various ETMs under optimal concentration conditions. The detailed photovoltaic cell parameters are listed in Table 1. As can be seen in Figure 2a, the PSCs with ITIC and COi8DFIC showed relatively poor diode characteristics compared to the PSC with IT-4F. In addition, the PSCs with ITIC and COi8DFIC showed similar photovoltaic cell parameters to each other and similar average PCEs of $8.01 \%$ (ITIC) and 8.04\% (COi8DFIC), as shown in Figure 2b,c, and Table 1. The PSCs with the IT-4f, in contrast, have better photovoltaic cell parameters, the PSCs with IT-4f exhibited an average $\mathrm{V}_{\mathrm{OC}}$ of $0.94 \mathrm{~V}$, an average $\mathrm{J}_{\mathrm{SC}}$ of $19.12 \mathrm{~mA} / \mathrm{cm}^{2}$, an average $\mathrm{FF}$ of $60.94 \%$, and an average PCE of $11.19 \%$. The best performing device with IT-4f exhibited a PCE of $12.11 \%$, while ITIC and COi8DFIC exhibited quite comparable PCEs of $8.37 \%$ and $8.55 \%$, respectively. It is clear to see that among the three non-fullerene ETMs, IT-4f had by far the best photovoltaic performance.

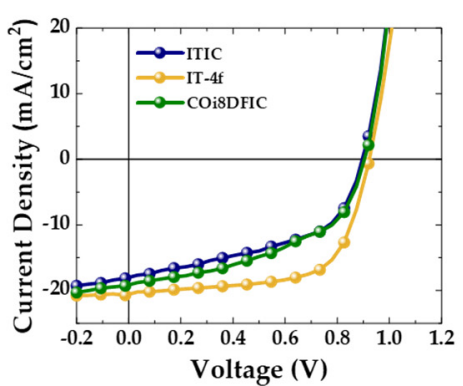

(a)

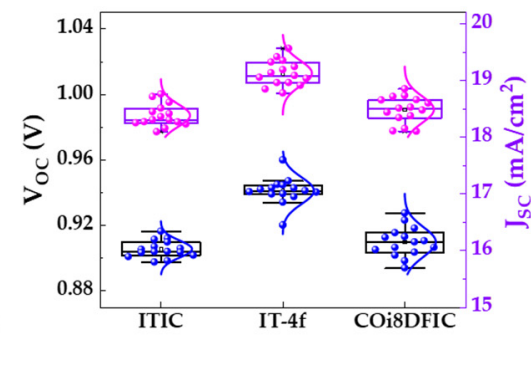

(b)

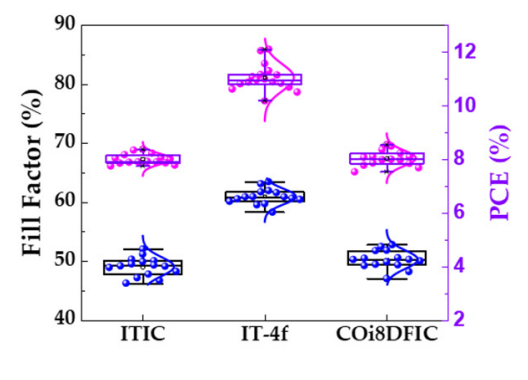

(c)

Figure 2. (a) Typical current density-voltage $(\mathrm{J}-\mathrm{V})$ curves and $(\mathbf{b}, \mathbf{c})$ statistical photovoltaic cell parameters of the PSC with various ETMs under optimal concentration conditions.

Table 1. Summary of statistical photovoltaic cell parameters of the PSC with various ETMs under optimal concentration conditions.

\begin{tabular}{cccccc}
\hline Sample & $\mathbf{V}_{\text {OC }}(\mathbf{V})$ & J SC $_{\left(\mathbf{m A} / \mathbf{c m}^{2}\right)}$ & FF (\%) & PCE (\%) & PCE $_{\text {MAX }}(\mathbf{\%})$ \\
\hline ITIC & $0.91( \pm 0.01)$ & $18.38( \pm 0.20)$ & $49.06( \pm 1.61)$ & $8.01( \pm 0.19)$ & 8.37 \\
IT-4f & $0.94( \pm 0.01)$ & $19.12( \pm 0.22)$ & $60.94( \pm 1.33)$ & $11.19( \pm 0.40)$ & 12.11 \\
COi8DFIC & $0.91( \pm 0.01)$ & $18.48( \pm 0.23)$ & $50.25( \pm 1.54)$ & $8.04( \pm 0.29)$ & 8.55 \\
\hline
\end{tabular}


In order to gain some insight into the electron extraction properties of the various ETLs, steady-state photoluminescence (PL) quenching measurements were performed on the perovskite film with and without NFSMs-based ETLs. As shown in Figure 3a, the change in the PL intensity of the perovskite film according to the introduction of non-fullerene ETMs was measured. The PL intensities of the perovskite films with non-fullerene ETM coatings were significantly reduced compared to that of the pristine perovskite film. Additionally, it was clearly observed that the perovskite film with the IT-4f ETM had a low PL intensity compared to those of ITIC and COi8DFIC, which indicates that the IT-4f possesses relatively better electron-extraction ability from the perovskite [28]. To further study charge recombination and charge transfer dynamics in the inverted planar PSCs with non-fullerene ETMs, transient photovoltage (TPV) and transient photocurrent (TPC) measurements were performed [18,29]. The average TPV and TPC decay times were calculated by fitting TPV and TPC curves using a biexponential decay function [18]. Figure $3 b$ and Table S1 show the average TPV decays of PSCs prepared with non-fullerene layers. It was found that the average TPV decay time and the charge recombination lifetime of the IT-4f-based device $(649 \mu \mathrm{s})$ are longer than those of both ITIC and COi8DFIC-based devices, these devices having quite similar average TPV decay times (ITIC-based device $(263 \mu \mathrm{s})$ and COi8DFIC-based device $(257 \mu \mathrm{s}))$, as shown in Figure $3 \mathrm{~b}$. The prolonged charge recombination lifetime suggests that charge recombination is efficiently suppressed with the introduction of IT- $4 \mathrm{f}$. Meanwhile, the average TPC decay time of the IT- $4 \mathrm{f}-\mathrm{based}$ device $(0.43 \mu \mathrm{s})$ was shorter than for ITIC and COi8DFIC, and the ITIC-based devices $(0.55 \mu \mathrm{s})$ and COi8DFIC-based devices $(0.56 \mu \mathrm{s})$ showed similar average TPC decay times, as shown in Figure $3 \mathrm{c}$ and Table S2. This indicates that the device with IT-4f layers has more efficient charge extraction and charge transport capabilities [16,30,31]. These TPV and TPC results are comprehensively consistent with previous J-V and PL measurements. More importantly, these TPV and TPC results suggest that the improved photovoltaic performance of the IT-4f-based PSCs can be ascribed to more efficient charge extraction and reduced recombination at the IT-4f/perovskite interface compared to ITIC and COi8DFIC.

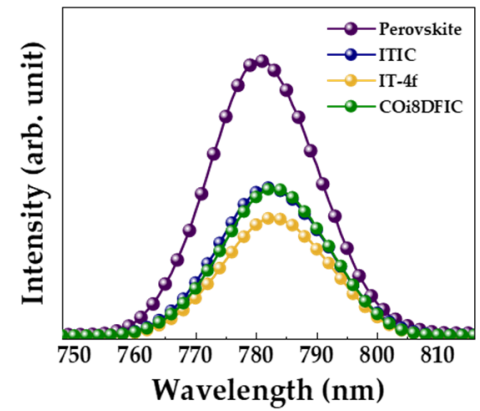

(a)

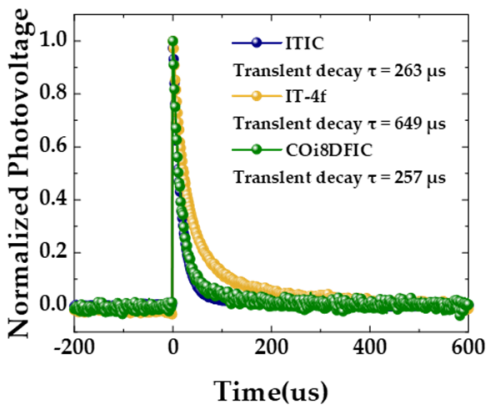

(b)

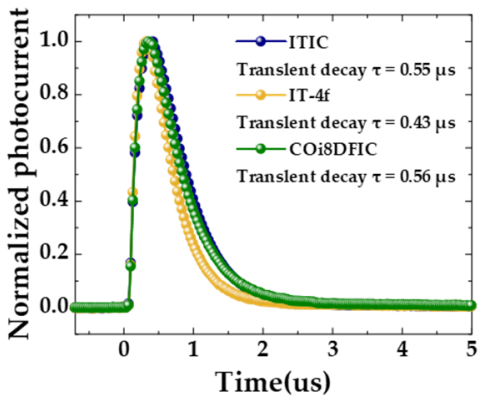

(c)

Figure 3. (a) Steady-state photoluminescence (PL) spectra of the perovskite, perovskite/ITIC, perovskite/IT-4f, and perovskite/COi8DFIC. (b) Transient photovoltage (TPV) and (c) transient photocurrent (TPC) curves of the PSC with ITIC, IT-4f, and COi8DFIC as ETLs.

To find out the reason for the enhanced performance and charge extraction capabilities shown by the IT-4f-based device, we first studied the surface morphologies of the non-fullerene ETMs on the perovskite layer by scanning electron microscopy (SEM) and atomic force microscopy (AFM). Figure 4a shows the top-view SEM images of ITIC, IT-4f, and COi8DFIC films on a perovskite layer. These SEM images for the ITIC, IT-4f, and COi8DFIC on a perovskite layer all show a full coverage film without any distinguishable pinholes or defects. Figure $4 \mathrm{~b}$ shows the AFM-based surface topographical images; it also shows the root mean square (RMS) roughness values of the ITIC, IT-4f, and COi8DFIC films coated on the perovskite layer, which are $9.83 \mathrm{~nm}, 11.47 \mathrm{~nm}$, and $9.70 \mathrm{~nm}$, respectively. After the introduction of NFSMs, the RMS roughness levels were all smoother compared to the pristine perovskite layer $(16.99 \mathrm{~nm})$. However, considering the ITIC and COi8DFIC showed 
similar RMS values and had better surfaces than IT-4f, and a smoother surface morphology could induce uniform contact between the perovskite layer and metal electrode for better charge transport and cell-efficiency [32,33]. This morphology analysis does not explain why the IT-4f-based device shows better performance. Next, since the energy level matching between the conduction band (CB) of perovskite and the lowest unoccupied molecular orbital (LUMO) of the ETL has a huge impact on PSC performance [28], based on previous reports, we investigated the energy level alignment between perovskite and NFSMs; the LUMO/HOMO values of the ITIC, IT-4f, and COi8DFIC are summarized as $-3.89( \pm 0.042) \mathrm{eV} /-5.48( \pm 0.014) \mathrm{eV},-4.14( \pm 0.035) \mathrm{eV} /-5.66( \pm 0.078) \mathrm{eV}$, and $-3.88 \mathrm{eV}$ $( \pm 0.148) /-5.50( \pm 0.021)$, respectively $[14,22,25-27]$. Figure $4 c$ presents the energy level diagram between the perovskite's CB and the ETL's LUMO and confirms that IT-4f provides better energy level matching with perovskite than ITIC and COi8DFIC, which could be favorable for charge extraction and cell-efficiency enhancement $[28,34]$. As shown in Figure 4d, similar trends were also confirmed by the series resistance (Rs) calculated from the J-V curve of the device manufactured under optimal concentration conditions; the same device used for the statistical data in Figure 2 was used. The average (Rs) value of IT- $4 \mathrm{f}\left(2.73 \pm 0.20 \Omega \mathrm{cm}^{2}\right)$ was lower than those of ITIC $\left(3.51 \pm 0.10 \Omega \mathrm{cm}^{2}\right)$ and COi8DFIC $\left(3.39 \pm 0.16 \Omega \mathrm{cm}^{2}\right)$. Based on these observations, it is believed that the better cell-parameters obtained with IT-4f could be mainly due to the better energy-level alignment between the ETL and photo active layer that results in enhanced electron transport and PSC-efficiency. All these facts come together to confirm that IT- $4 \mathrm{f}$ is a more promising candidate for use in high performance PSCs. This conclusion and the associated data are also supported by the conductive atomic force microscopy (C-AFM) that measures the current-flow between the sample and the AFM tip. As shown in Figure 4e, IT-4f has a higher average current (15.20 pA) than ITIC (4.32 pA) and COi8DFIC (3.02 pA); this indicates more efficient charge collection at the IT-4f ETL that might be caused by a lower injection barrier and a better ohmic contact [35-39].

To confirm the potential of IT- $4 \mathrm{~F}$ as an alternative electron transport material, we fabricated the device with $\mathrm{PC}_{61} \mathrm{BM}$, commonly used as an electron transport material, and performed comparative analysis with the performance of IT- $4 \mathrm{~F}$ based devices. As can be seen from the statistical photovoltaic cell parameters for IT- $4 \mathrm{f}$ and $\mathrm{PC}_{61}$ BM-based devices shown in Figure 5a,b, IT-4f-based devices showed performance parameters similar to those of the $\mathrm{PC}_{61} \mathrm{BM}$-based devices, resulting in an average PCE of $11.27 \%$, similar to that of PCBM-based devices (11.57\%). These results indicate that It- $4 \mathrm{~F}$ has potential as an alternative ETL. However, SEM and AFM analysis and energy level diagrams for PCBM suggest that there may be a trade-off between surface properties and energy levels of in the case of IT-4F. As shown in Figure S2, PCBM has a smoother surface $(7.50 \mathrm{~nm})$ than IT-4f $(11.47 \mathrm{~nm})$, which can lead to a relatively higher FF than for IT-4F-based devices [40,41]. On the other hand, as illustrated in Figure $4 \mathrm{c}$ and Figure S2c, IT-4F has a relatively deeper and better matched LUMO level $(-4.14 \mathrm{eV})$ than PCBM $(-3.91 \mathrm{eV})$, and thus may exhibit more efficient charge collection ability, resulting in a relatively high Jsc compared to PCBM-based devices [40]. This can be supported by the results of the C-AFM of the IT-4F and PCBM, as shown in Figure 4e and Figure S2d. Therefore, considering the surface roughness, it can be determined that the IT-4F-based device exhibits similar performance to the PCBM-based device due to the LUMO that is relatively well matched with CB of the perovskite. The stability of unencapsulated devices using IT- $4 \mathrm{f}$ and $\mathrm{PC}_{61} \mathrm{BM}$ was also investigated because ETL in the p-i-n structure could have a significant impact on the stability of PSCs; corresponding results are shown in Figure $5 \mathrm{c}$. The devices were stored indoors at $\sim 23^{\circ} \mathrm{C}$ under $\sim 55 \%$ relative humidity in ambient air conditions prior to measurement. The efficiency of the IT-4f-based device was reduced to $55.9 \%$ after $664 \mathrm{~h}$ and that of the $\mathrm{PC}_{61} \mathrm{BM}$-based device was reduced to $57.3 \%$ after identical exposure time; this demonstrates the quite similar stability of both devices. From this result, it can be implied that the IT- $4 \mathrm{f}$ is a suitable material to be used as a $\mathrm{PC}_{61} \mathrm{BM}$-alternative ETL in high performance PSCs. 

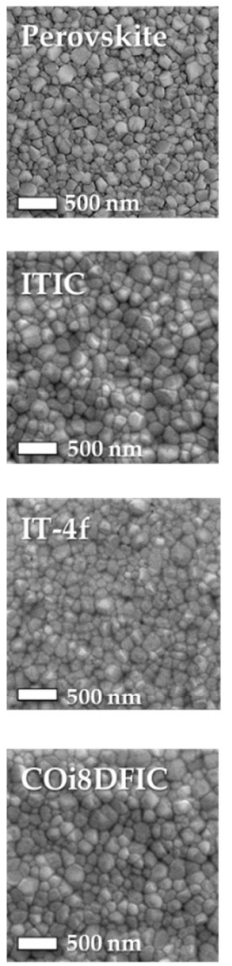

(a)
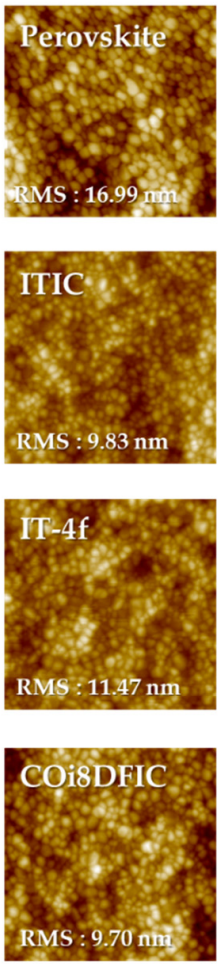

(b)

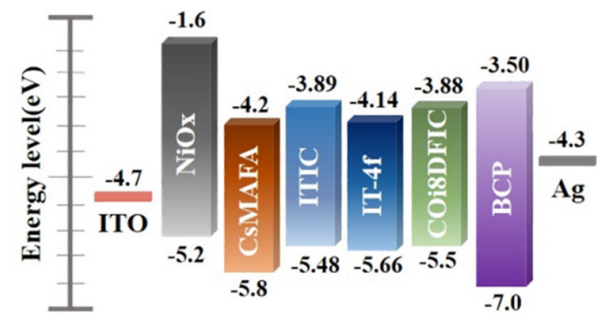

(c)

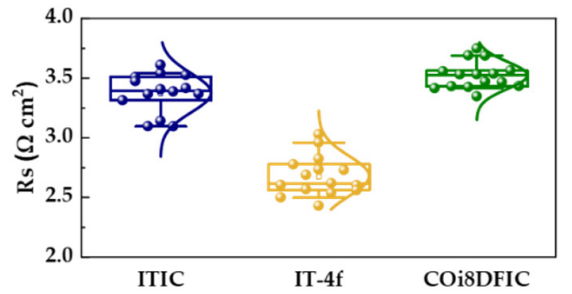

(d)
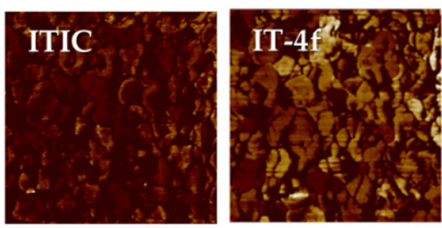

(e)

Figure 4. (a) Top-view SEM and (b) AFM images (scale: $5 \times 5 \mu \mathrm{m}$ ) of ITIC, IT-4f, and COi8DFIC films coated on the ITO/NiO $/$ perovskite layer. (c) Schematic energy level diagram of the perovskite and non-fullerene ETMs. (d) Series resistance (Rs) calculated from the J-V curve of the device manufactured under optimal concentration conditions. (e) C-AFM images (scale: $2 \times 2 \mu \mathrm{m}$ ) of ITIC, IT-4f, and COi8DFIC films.

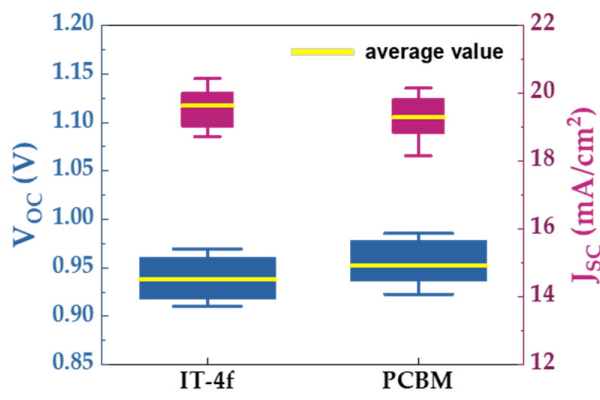

(a)

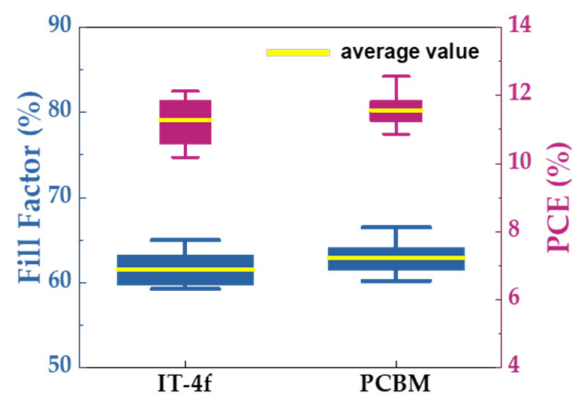

(b)

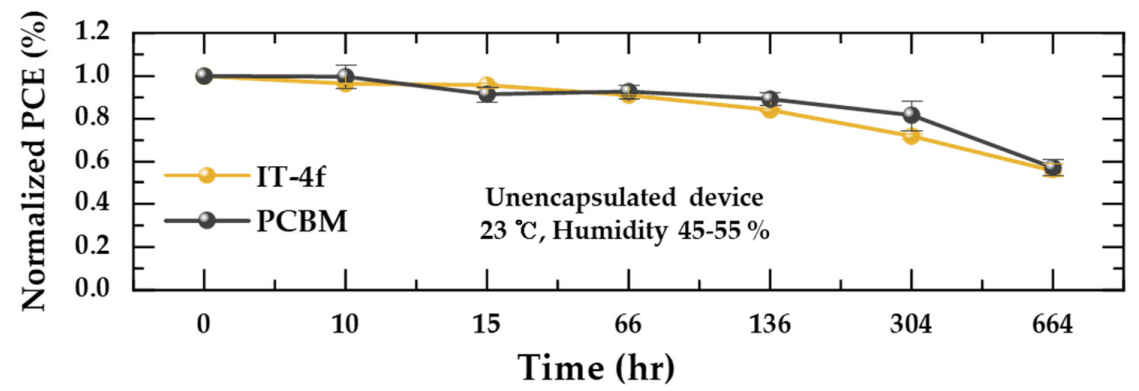

(c)

Figure 5. (a,b) Statistical photovoltaic cell parameters of the PSC with IT-4f and PCBM. (c) Changes in power conversion efficiency of the PSC with IT- $4 \mathrm{f}$ and PCBM. 


\section{Conclusions}

In summary, we systematically investigated the use of solution-processable NFSMs as ETLs for high-performance inverted PSCs. We introduced ITIC, IT-4F, and COi8DFIC for use as ETLs in inverted PSCs as part of a search for an improved alternative to $\mathrm{PC}_{61} \mathrm{BM}$ layers. It was found that IT-4f showed the best performance of all the investigated non-fullerene candidates. Various device and film-property analyses revealed that using IT-4f, the device showed superior charge extraction and enhanced suppressed charge recombination, and the energy-level alignment was better matched with the perovskite, resulting in improved photovoltaic performances. Furthermore, when comparing the IT-4f device with the widely used $\mathrm{PC}_{61} \mathrm{BM}$ device, it was found that the efficiency and stability of the IT-4f based PSC (11.75\%) are quite alike those of the $\mathrm{PC}_{61}$ BM-based PSCs. Our future work will focus on finding other non-fullerene ETLs with the aim of comprehensively improving on the present $\mathrm{PC}_{61} \mathrm{BM}$-alternatives to produce even higher performance PSCs.

Supplementary Materials: The following are available online at http://www.mdpi.com/2079-4991/10/6/1082/s1. Figure S1: Current density-voltage (J-V) curves of the PSC according to the concentration change of (a) ITIC, (b) IT-4f, and (c) COi8DFIC. Figure S2: (a) Top-view SEM and (b) AFM images (scale: $5 \times 5 \mu \mathrm{m}$ ) of PCBM films coated on the ITO/NiOx/perovskite layer. (c) Schematic energy level diagram of the perovskite and PCBM ETLs. (d) C-AFM image (scale: $2 \times 2 \mu \mathrm{m}$ ) of the PCBM film. Table S1: Fitting parameters of bi-exponential decay function in transient photovoltage measurement. Table S2: Fitting parameters of bi-exponential decay function in transient photocurrent measurement.

Author Contributions: Conceptualization, methodology, investigation, writing-original draft preparation, D.-S.C.; formal analysis, data curation, writing-review and editing, supervision, S.-N.K.; conceptualization, supervision, project administration, funding acquisition, writing-review and editing, S.-I.N. All authors have read and agreed to the published version of the manuscript.

Funding: This work was supported by the Korea Electric Power Corporation (KEPCO) (CX72170050), and the Korea Institute for Advancement of Technology (KIAT) grant funded by the Korea Government (MOTIE) (P0002007), and the selection of research-oriented professor of Jeonbuk National University in 2020.

Acknowledgments: The authors acknowledge the Korea Basic Science Institute (KBSI) for providing C-AFM. and Korea Institute of Industrial Technology (KITECH) for providing SEM.

Conflicts of Interest: The authors declare no conflict of interest.

\section{References}

1. Yusoff, A.R.; Nazeeruddin, M.K. Organohalide Lead Perovskites for Photovoltaic Applications. J. Phys. Chem. Lett. 2016, 7, 851-866. [CrossRef] [PubMed]

2. Yang, D.; Yang, R.; Priya, S.; Liu, S.F. Recent Advances in Flexible Perovskite Solar Cells: Fabrication and Applications. Angew. Chem. Int. Ed. Engl. 2019, 58, 4466-4483. [CrossRef] [PubMed]

3. Yeo, J.-S.; Kang, R.; Lee, S.; Jeon, Y.-J.; Myoung, N.; Lee, C.-L.; Kim, D.-Y.; Yun, J.-M.; Seo, Y.-H.; Kim, S.-S.; et al. Highly efficient and stable planar perovskite solar cells with reduced graphene oxide nanosheets as electrode interlayer. Nano Energy 2015, 12, 96-104. [CrossRef]

4. NREL. Available online: https://www.nrel.govpvassetspdfsbest-research-cell-efficiencies (accessed on 6 April 2020).

5. Lee, J.; Seo, Y.-H.; Kwon, S.-N.; Kim, D.-H.; Jang, S.; Jung, H.; Lee, Y.; Weerasinghe, H.; Kim, T.; Kim, J.Y.; et al. Slot-Die and Roll-to-Roll Processed Single Junction Organic Photovoltaic Cells with the Highest Efficiency. Adv. Energy Mater. 2019, 9, 1901805. [CrossRef]

6. Shi, Z.; Jayatissa, A.H. Perovskites-Based Solar Cells: A Review of Recent Progress, Materials and Processing Methods. Materials 2018, 11, 729. [CrossRef]

7. Pham, H.D.; Li, X.; Li, W.; Manzhos, S.; Kyaw, A.K.K.; Sonar, P. Organic interfacial materials for perovskite-based optoelectronic devices. Energy Environ. Sci. 2019, 12, 1177-1209. [CrossRef]

8. Lee, K.; Ryu, J.; Yu, H.; Yun, J.; Lee, J.; Jang, J. Enhanced efficiency and air-stability of NiOX-based perovskite solar cells via PCBM electron transport layer modification with Triton X-100. Nanoscale 2017, 9, 16249-16255. [CrossRef] 
9. Chen, W.; Xu, L.; Feng, X.; Jie, J.; He, Z. Metal Acetylacetonate Series in Interface Engineering for Full Low-Temperature-Processed, High-Performance, and Stable Planar Perovskite Solar Cells with Conversion Efficiency over $16 \%$ on $1 \mathrm{~cm}^{2}$ Scale. Adv. Mater. 2017, 29, 1603923. [CrossRef]

10. Kwon, S.-N.; Yu, J.-H.; Na, S.-I. A systematic approach to ZnO nanoparticle-assisted electron transport bilayer for high efficiency and stable perovskite solar cells. J. Alloy. Compd. 2019, 801, 277-284. [CrossRef]

11. Xu, J.; Buin, A.; Ip, A.H.; Li, W.; Voznyy, O.; Comin, R.; Yuan, M.; Jeon, S.; Ning, Z.J.J.; Kanjanaboos, P.; et al. Perovskite-fullerene hybrid materials suppress hysteresis in planar diodes. Nat. Commun. 2015, 6, 7081. [CrossRef]

12. Chen, K.; Hu, Q.; Liu, T.; Zhao, L.; Luo, D.; Wu, J.; Zhang, Y.; Zhang, W.; Liu, F.; Russell, T.P.; et al. Charge-Carrier Balance for Highly Efficient Inverted Planar Heterojunction Perovskite Solar Cells. Adv. Mater. 2016, 28, 10718-10724. [CrossRef] [PubMed]

13. Ip, A.H.; Quan, L.N.; Adachi, M.; McDowell, M.; Jeffrey, J.; Xu, J.; Kim, D.H.; Sargent, E.H. A two-step route to planar perovskite cells exhibiting reduced hysteresis. Appl. Phys. Lett. 2015, 106, 143902. [CrossRef]

14. Angmo, D.; Peng, X.; Cheng, J.; Gao, M.; Rolston, N.; Sears, K.; Zuo, C.; Subbiah, J.; Kim, S.S.; Weerasinghe, H.; et al. Beyond Fullerenes: Indacenodithiophene-Based Organic Charge-Transport. Layer toward Upscaling of Low-Cost Perovskite Solar Cells. ACS Appl. Mater. Interfaces 2018, 10, 22143-22155. [CrossRef] [PubMed]

15. Volker, S.F.; Valles-Pelarda, M.; Pascual, J.; Collavini, S.; Ruiperez, F.; Zuccatti, E.; Hueso, L.E.; Tena-Zaera, R.; Mora-Sero, I.; Delgado, J.L. Fullerene-Based Materials as Hole-Transporting/Electron.-Blocking Layers: Applications in Perovskite Solar Cells. Chemistry 2018, 24, 8524-8529. [CrossRef] [PubMed]

16. Guo, Y.; Ma, J.; Lei, H.; Yao, F.; Li, B.; Xiong, L.; Fang, G. Enhanced performance of perovskite solar cells via anti-solvent nonfullerene Lewis base IT-4F induced trap-passivation. J. Mater. Chem. A 2018, 6, 5919-5925. [CrossRef]

17. Chen, B.; Rudd, P.N.; Yang, S.; Yuan, Y.; Huang, J. Imperfections and their passivation in halide perovskite solar cells. Chem. Soc. Rev. 2019, 48, 3842-3867. [CrossRef]

18. Choi, M.-J.; Lee, Y.-S.; Cho, I.H.; Kim, S.-S.; Kim, D.-H.; Kwon, S.-N.; Na, S.-I. Functional additives for high-performance inverted planar perovskite solar cells with exceeding 20\% efficiency: Selective complexation of organic cations in precursors. Nano Energy 2020, 71, 104639. [CrossRef]

19. Chang, C.-Y.; Huang, W.-K.; Chang, Y.-C.; Lee, K.-T.; Chen, C.-T. A solution-processed n-doped fullerene cathode interfacial layer for efficient and stable large-area perovskite solar cells. J. Mater. Chem. A 2016, 4, 640-648. [CrossRef]

20. Rolston, N.; Watson, B.; Bailie, C.D.; McGehee, M.D.; Bastos, J.P.; Gehlhaar, R.; Kim, J.-E.; Vak, D.; Mallajosyula, A.T.; Gupta, G.; et al. Mechanical integrity of solution-processed perovskite solar cells. Extrem. Mech. Lett. 2016, 9, 353-358. [CrossRef]

21. Bae, J.-H.; Noh, Y.-J.; Kang, M.; Kim, D.-Y.; Kim, H.-B.; Oh, S.-H.; Yun, J.-M.; Na, S.-I. Enhanced performance of perovskite solar cells with solution-processed n-doping of the PCBM interlayer. RSC Adv. 2016, 6, 64962-64966. [CrossRef]

22. Noh, Y.-J.; Jeong, J.-H.; Kim, S.-S.; Kim, H.-K.; Na, S.-I. Non-fullerene-based small molecules as efficient n-type electron transporting layers in inverted organic-inorganic halide perovskite solar cells. J. Ind. Eng. Chem. 2018, 65, 406-410. [CrossRef]

23. Na, S.-I.; Seo, Y.-H.; Nah, Y.-C.; Kim, S.-S.; Heo, H.; Kim, J.-E.; Rolston, N.; Dauskardt, R.H.; Gao, M.; Lee, Y.; et al. High Performance Roll-to-Roll Produced Fullerene-Free Organic Photovoltaic Devices via Temperature-Controlled Slot Die Coating. Adv. Funct. Mater. 2018, 29. [CrossRef]

24. Jiang, J.; Jin, Z.; Lei, J.; Wang, Q.; Zhang, X.; Zhang, J.; Gao, F.; Liu, S. ITIC surface modification to achieve synergistic electron transport layer enhancement for planar-type perovskite solar cells with efficiency exceeding 20\%. J. Mater. Chem. A 2017, 5, 9514-9522. [CrossRef]

25. Lin, Y.; Wang, J.; Zhang, J.; Bai, H.; Li, Y.; Zhu, D.; Zhan, X. An Electron Acceptor Challenging Fullerenes for Efficient Polymer Solar Cells. Adv. Mater. 2015, 27, 1170-1174. [CrossRef]

26. Yang, Y.; Zhang, J.; Bin, H.; Chen, S.; Gao, L.; Xue, L.; Yang, C.; Li, Y. Side-Chain Isomerization on an n-type Organic Semiconductor ITIC Acceptor Makes 11.77\% High Efficiency Polymer Solar Cells. J. Am. Chem. Soc. 2016, 138, 15011-15018. [CrossRef]

27. Li, W.; Xiao, Z.; Smith, J.A.; Cai, J.; Li, D.; Kilbride, R.C.; Spooner, E.L.K.; Game, O.S.; Meng, X.; Liu, D.; et al. Enhancing the efficiency of PTB7-Th:COi8DFIC-based ternary solar cells with versatile third components. Appl. Phys. Rev. 2019, 6, 041405. [CrossRef] 
28. Liu, X.; Li, X.; Zou, Y.; Liu, H.; Wang, L.; Wan, L.; Yang, C. Energy level-modulated non-fullerene small molecule acceptors for improved VOC and efficiency of inverted perovskite solar cells. J. Mater. Chem. A 2019, 7, 3336-3343. [CrossRef]

29. Snaith, H.J. Perovskites: The Emergence of a New Era for Low-Cost, High-Efficiency Solar Cells. J. Phys. Chem. Lett. 2013, 4, 3623-3630. [CrossRef]

30. Lan, C.; Zhou, Z.; Wei, R.; Ho, J.C. Two-dimensional perovskite materials: From synthesis to energy-related applications. Mater. Today Energy 2019, 11, 61-82. [CrossRef]

31. Dong, H.; Pang, S.; Zhang, Y.; Chen, D.; Zhu, W.; Xi, H.; Chang, J.; Zhang, J.; Zhang, C.; Hao, Y. Improving Electron Extraction Ability and Device Stability of Perovskite Solar Cells Using a Compatible PCBM/AZO Electron Transporting Bilayer. Nanomaterials 2018, 8, 720. [CrossRef]

32. Yun, J.-M.; Yeo, J.-S.; Kim, J.; Jeong, H.-G.; Kim, D.-Y.; Noh, Y.-J.; Kim, S.-S.; Ku, B.-C.; Na, S.-I. Solution-Processable Reduced Graphene Oxide as a Novel Alternative to PEDOT:PSS Hole Transport Layers for Highly Efficient and Stable Polymer Solar Cells. Adv. Mater. 2011, 23, 4923-4928. [CrossRef] [PubMed]

33. Noh, Y.-J.; Park, S.-C.; Hwang, I.-T.; Choi, J.-H.; Kim, S.-S.; Jung, C.-H.; Na, S.-I. High-performance polymer solar cells with radiation-induced and reduction-controllable reduced graphene oxide as an advanced hole transporting material. Carbon 2014, 79, 321-329. [CrossRef]

34. Lim, K.-G.; Ahn, S.; Kim, Y.-H.; Qi, Y.; Lee, T.-W. Universal energy level tailoring of self-organized hole extraction layers in organic solar cells and organic-inorganic hybrid perovskite solar cells. Energy Environ. Sci. 2016, 9, 932-939. [CrossRef]

35. Meier, D.; Schroder, D. Contact resistance: Its measurement and relative importance to power loss in a solar cell. IEEE Trans. Electron Devices 1984, 31, 647-653. [CrossRef]

36. Douhéret, O.; Lutsen, L.; Swinnen, A.; Breselge, M.; Vandewal, K.; Goris, L.; Manca, J.V. Nanoscale electrical characterization of organic photovoltaic blends by conductive atomic force microscopy. Appl. Phys. Lett. 2006, 89, 32107. [CrossRef]

37. Yip, H.-L.; Jen, A.-Y. Recent advances in solution-processed interfacial materials for efficient and stable polymer solar cells. Energy Environ. Sci. 2012, 5, 5994. [CrossRef]

38. Hau, S.K.; Yip, H.-L.; Acton, O.; Baek, N.S.; Ma, H.; Jen, A.-Y. Interfacial modification to improve inverted polymer solar cells. J. Mater. Chem. 2008, 18, 5113-5119. [CrossRef]

39. Cui, P.; Fu, P.; Wei, D.; Li, M.; Song, D.; Yue, X.; Li, Y.; Zhang, Z.; Li, Y.; Mbengue, J.M. Reduced surface defects of organometallic perovskite by thermal annealing for highly efficient perovskite solar cells. RSC Adv. 2015, 5, 75622-75629. [CrossRef]

40. Kim, H.I.; Kim, M.-J.; Choi, K.; Lim, C.; Kim, Y.-H.; Kwon, S.-K.; Park, T. Improving the Performance and Stability of Inverted Planar Flexible Perovskite Solar Cells Employing a Novel NDI-Based Polymer as the Electron Transport Layer. Adv. Energy Mater. 2018, 8, 1702872. [CrossRef]

41. Ye, J.; Zhang, X.; Zhu, L.; Zheng, H.; Liu, G.; Wang, H.; Hayat, T.; Pan, X.; Dai, S. Enhanced morphology and stability of high-performance perovskite solar cells with ultra-smooth surface and high fill factor via crystal growth engineering. Sustain. Energy Fuels 2017, 1, 907-914. [CrossRef]

(C) 2020 by the authors. Licensee MDPI, Basel, Switzerland. This article is an open access article distributed under the terms and conditions of the Creative Commons Attribution (CC BY) license (http://creativecommons.org/licenses/by/4.0/). 